Int. J. Dev. Biol. 50: 413-421 (2006)

doi: $10.1387 / \mathrm{ijdb} .052100 \mathrm{cc}$

Original Article

\title{
Germ-plasm specification and germline development in the parthenogenetic pea aphid Acyrthosiphon pisum: Vasa and Nanos as markers
}

\author{
CHUN-CHE CHANG ${ }^{1}{ }^{*}$, WEN-CHIH LEE ${ }^{2}$, CHARLES E. COOK ${ }^{3}$, GEE-WAY LIN ${ }^{1}$ AND TSCHINING CHANG ${ }^{4}$ \\ ${ }^{1}$ Laboratory for Genetics and Development, Department of Entomology, National Taiwan University, Taipei, Taiwan, ${ }^{2}$ Institute of \\ Molecular Biology, Academia Sinica, Taipei, Taiwan, ${ }^{3}$ University Museum of Zoology, University of Cambridge, U.K. and ${ }^{4}$ Institute of \\ Biological Chemistry, Academia Sinica, Taipei, Taiwan
}

\begin{abstract}
The germarium, oocytes and embryos of the parthenogenetic viviparous pea aphid Acyrthosiphon pisum are contained within a single ovariole. This species provides an excellent model for studying how maternally-inherited germ plasm is specified and how it is transferred to primordial germ cells. Previous studies have shown that germ cells are first segregated at the embryonic posterior after formation of the blastoderm. We used two cross-reacting antibodies against the conserved germline markers Vasa and Nanos, which specifically identified these presumptive germ cells, to investigate whether germ cells were determined during early development. We observed randomly-distributed weak expression of Vasa signals in the developing oocyte but no localization in the oocyte segregated from the germarium. Localized Vasa was not apparent until it was detected at the posterior in the embryo undergoing the second nuclear division. Nanos, on the other hand, was localized to a nuage-like structure surrounding the nucleus in the developing and segregated oocytes. At the beginning of the oocyte maturation division, Nanos localization shifted to the posterior and could be identified in successive stages until it was incorporated into the germ cells. Taken together, our results suggest that germ plasm is specified in the developing oocyte and that Nanos is an earlier germline marker than Vasa. Presumptive germ cells stained for Vasa remained at a dorsal location in the egg during middevelopment and then were guided into abdominal segments A1 to A6 during germ-band retraction. We infer that germ cells coalesce with segmented gonadal mesoderm during this period.
\end{abstract}

KEY WORDS: Acyrthosiphon pisum, pea aphid, germ cell, Vasa, Nanos

\section{Introduction}

In most animals, including insects, adult gametes arise from germ cells that are specified during embryogenesis (Saffman and Lasko, 1999; Extavour and Akam, 2003). In the model insect Drosophila melanogaster, the primordial germ cells, or pole cells, are determined by maternally-inherited germ plasm at the posterior region of the egg. By the time of blastoderm formation, the polar granules, which contain germ-cell determinants in the germ plasm, are incorporated into the first cellularized cells at the posterior pole of the embryo. These cells then become primordial germ cells (Swanson and Poodry, 1980). In other dipterans such as the cecidomyid Miastor metraloas and several species of the genus Chironomous, pole cells are also identified in early embryos by the presence of an "oösome" (Leuckart, 1865), which is currently known as the germ, or pole plasm. This mechanism, by which germ cells are determined from inherited cytoplasmic markers, is known as "preformation". However, in some insects such as the grasshopper Schistocerca gregaria, no maternal germ plasm can be identified and germ cells are segregated at much later developmental stages in the abdominal margin when segmentation is initiated in the abdomen. It is believed that the formation of these primordial germ cells is induced by signals from adjacent somatic cells (Chang et al., 2002). In other insects such as Bombyx mori (Lepidoptera) (Nakao, 1999), Apis mellifera (Hymenoptera) (Nelson, 1915) and Hydrophilus piceus (Coleoptera) (Hegner, 1908), germ-cell segregation is also not detected until late gastrulation. This mechanism, whereby germ

Abbreviations used in this paper: PGC, primordial germ cell. 
Fig. 1. Vas and Nos signals in germaria and oocytes (stage $\mathbf{0}$ to stage 1 of development). Signals representing Vas or Nos immunoactivity, F-actin adjacent to the inner surface of cell membranes and nuclei are indicated with color keys under the figure. Anterior is to the left and posterior is to the right in all panels. Confocal images showing Vas $(A, E)$ or Nos $(B, F)$ antibody staining. Confocal images showing merged results from Vas $(C, G)$ and Nos $(D, H)$ antibodies, nuclei and F-actin stainings. DIC images of Vas (I) and Nos (J). (A-D) Germaria and developing oocytes (stage (st.) 0 of development). (A,C) Vas signals are localized to the cytoplasm (arrow) in nurse cells ( $n$ ) and prospective oocytes (poc; with condensed chromatin at the germarium posterior part (Miura et al., 2003)) within the germarium (g). Weak Vas signals are randomly distributed in the cytoplasm of the oocyte (o) with some near the periphery of the oocyte nucleus (on). (B,D) Nos signals are localized to the cytoplasm (arrow) in nurse cells (n), prospective oocytes (poc) and the periphery (arrowhead) of the oocyte nucleus (on). Weak expression of Nos signals in nuclei (nu) in the germarium is visible. (EJ) Germaria and separated oocytes (stage 1 of development). Abbreviations and markings are the same as those in A-D. $(\mathbf{E}, \mathbf{G}, \mathbf{I})$ Localized Vas signals are not visible in the cytoplasm and nuclear periphery (hollow arrowhead) in the oocyte. The thinner shape of the ovary in $(E, G)$ was caused by slight stretching of ovarioles during sample preparation. $(\mathbf{F}, \mathbf{H}, \mathbf{J})$ Localized Nos signals are detected in the cytoplasm (arrow) as well as in the nuclear periphery (arrowhead). I and $J$ are not the same individual as $(E, G)$ and $(F, H)$ respectively. $f c$, follicle cell; $t f$, terminal filament. Scale bars: $20 \mu \mathrm{m}$.

cells are determined through signal-inductive pathways later in embryogenesis, is known as "epigenesis". These examples demonstrate that germ cell specification in insects is quite diversified. Indeed, even within the order Coleoptera the timing of germ-cell segregation is different between species. For example, in the weevil Calandra granaria germ cells are identified during the formation of the blastoderm while in the aquatic beetle $H$. piceus they are first noticeable after the formation of the ceolomic sac (Heider, 1889; Inkmann, 1933; Johannsen and Butt, 1941).

We studied germline development in the parthenogenetic pea aphid Acyrthosiphon pisum because oogenesis and embryogenesis in this species occur within a single ovariole, thus providing an excellent model for investigating how germ plasm in the oocyte, if there is any, is transferred to the embryonic germ cells. In the telotrophic-type ovariole of $A$. pisum the germline stem cells are located in a 32-cell germarium, from which a single oocyte is derived. This oocyte begins to cleave and thereafter develops, without fertilization, directly into an embryo (Büning, 1985; Blackman, 1987; Miura et al., 2003). The formation of the blastoderm in Acyrthosiphonis similar to that in Drosophila where cleavage nuclei derived from the oocyte nucleus migrate toward the embryo periphery to form a syncytial blastoderm, which then becomes a single-layer germ band after cellularization (Miura et al., 2003). Previous studies relying on morphological observation show that the earliest primordial germ cells, identified by their display of granular material, occur at the posterior region of the embryo after cellularization. During early gastrulation, these primordial germ cells are pushed to migrate by the elongating germ band and are associated with the maternal endosymbiotic bacteria transferred into the embryonic cavity by gastrulation (Will, 1888; Hagan, 1951; Miura et al., 2003). How-
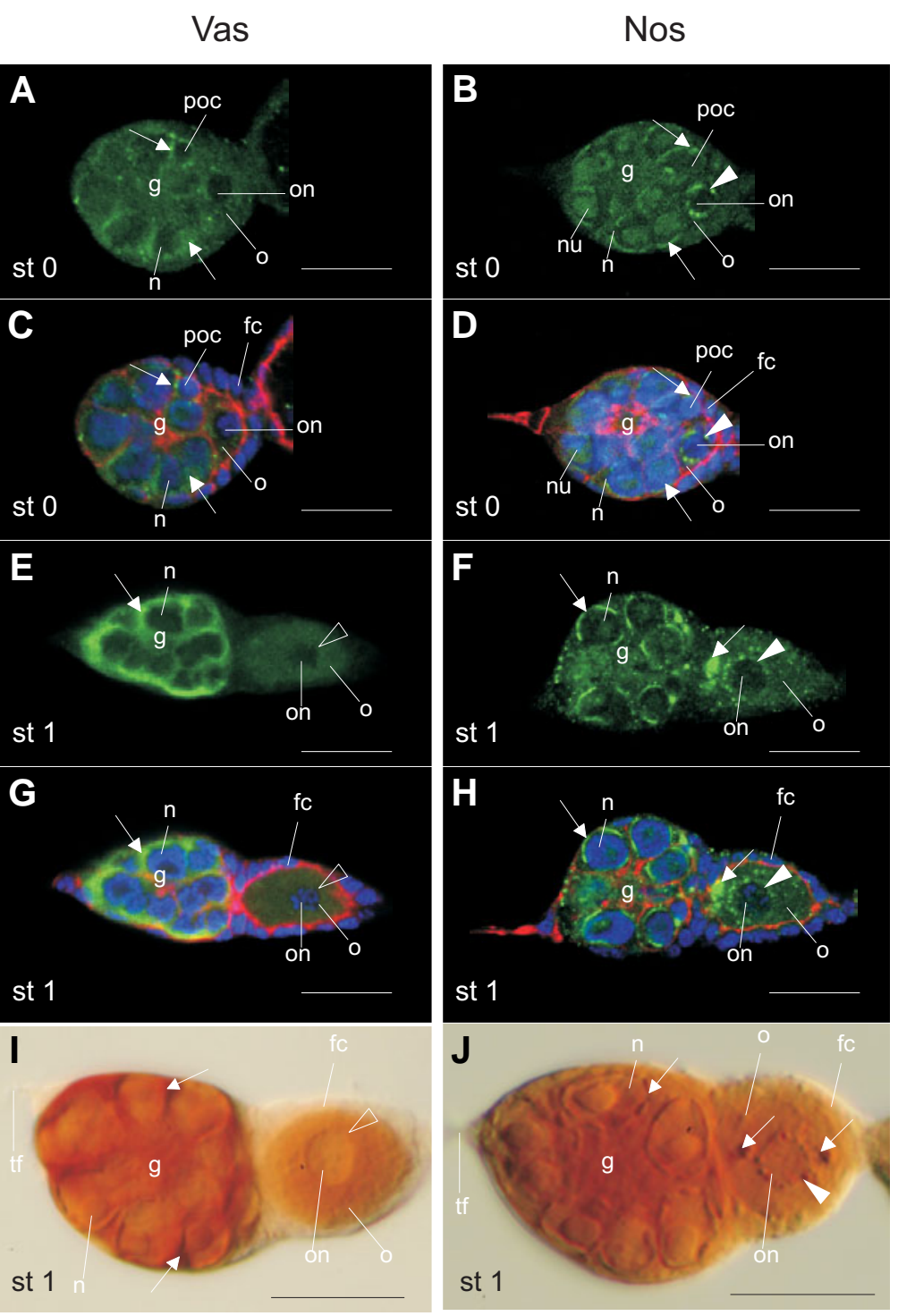

Vas/Nos

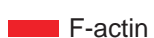

Nuclei

ever, whether the granular material identified in the early presumptive germ cells are germline determinants, where the earliest germ plasm is and how it is transferred to the germ cells are almost unknown. In addition, little is known about how germ cells are patterned after the embryo flips (ketatrepsis) during late embryogenesis, except for a few drawings of young ovarioles in mature embryos (Will, 1888; Hagan, 1951; Büning, 1985). We therefore applied molecular methods using cross-reacting antibodies against two conserved germline markers, Vasa and Nanos, to investigate the specification of germ plasm during early development and the location of germ cells in late embryos during the parthenogenetic reproductive phase in $A$. pisum.

The vasagene, first identified in $D$. melanogaster, encodes an ATP-dependent RNA helicase belonging to the DEAD-box protein family. In Drosophilathe Vasa protein is a component of the maternal germ plasm and it is identified in germ cells throughout all developmental stages (Hay etal., 1988b; Lasko and Ashburner, 1988). During oogenesis, Vasa is involved in the translation of 
gurken, which is essential for establishing the posterior region of the oocyte (Styhler etal., 1998; Tomancak et al., 1998) and during early embryogenesis Vasa regulates the translation of oskarand nanos, whose gene products are also components of the germ plasm (Gavis et al., 1996; Markussen et al., 1997; Carrera et al., 2000). In insects, loss-of-function assays of vasa only have been reported in flies and wasps. Progeny produced by females homozygous for Drosophila vasa mutations show defects in posterior structures and pole cells (Hay et al., 1988b; Lasko and Ashburner, 1988). In the four cell-stage embryo of the wasp Copidosoma floridanum, the ablation of the Vasa-positive blastomere that gives rise to a primordial germ cell leads to the production of soldier broods, rather than reproductive larvae, in the majority of the population. This indicates that vasais involved in germ-cell proliferation and caste formation in wasps (Donnell et al., 2004; Zhurov et al., 2004). Evidence showing that vasa is a highly conserved germline marker in other metazoan species is reviewed in Bratt et al. (1999), Saffman and Lasko (1999), Raz (2000) and Extavour and Akam (2003).

In this study, we use a highly cross-reacting antibody against Vasa to stain the germ cells in parthenogenetic aphids. This antibody has successfully cross-reacted with germ cells in $\mathcal{S}$. gregaria (grasshopper) (Chang et al., 2002), D. melanogaster (fly) (Chang et al., 2002), C. floridanum (wasp) (Grbic, 2000), Parhyale hawaiensis (amphipod crustacean) (Extavour, 2005) and Nematostella vectensis (sea anemone) (Extavour et al., 2005). We expected it could also target the aphid germ cells. We note, however, that although vasa or its gene product is a highly conserved germline marker, in several species it is not identified in the early germ plasm. For example, neither XVLG1 (Xenopus vasa-like gene 1) mRNA nor XVLG1 protein are specifically detected in the mitochondrial cloud, from which the maternal germ plasm is derived. XVLG1 is not restricted to the germ cells until stage 46 tadpoles (Komiya et al., 1994; Ikenishi and Tanaka, 2000). X-cat2, a Drosophila nanos homologue in Xenopus, is expressed in the mitochondrial cloud in the stage I oocyte (Mosquera et al., 1993). Another similar case showing that vasa is not the earliest germline marker occurs in mice: fragilis, stella and nanos 3 are first identified in migrating primordial germ cells by the time order of embryonic days (E) 6.25, 7.0 and 9.5 respectively (Saitou et al., 2002; Tsuda et al., 2003), whereas the Mvh (mouse vasa homologue) protein is detected later in germ cells colonized in the gonad at E10.5 (Fujiwara et al., 1994). Accordingly, we in parallel stained aphids with an antibody against
Fig. 2. Vas and Nos signals in oocytes and early embryos undergoing nuclear division (stage 2 to stage 3 of development). Signals representing Vas or Nos immunoactivity, F-actin adjacent to the inner surface of cell membranes and nuclei are indicated with color keys under the figure. Anterior is to the left and posterior is to the right in all panels. Confocal images showing Vas $(A, F, J, N)$ or Nos $(C, D, H, P)$ antibody staining; ( $L)$ negative control (-ctrl). Confocal images showing merged results from Vas $(B, G, K, O)$ and Nos $(E, I, Q)$ antibody staining, with nucleiand F-actin stainings; (M) -ctrl. (A-E) Oocytes undergoing maturation division (stage (st) 2 of development). (A,B) Vas signals (arrow) are distributed in about one third of the cytoplasm adjacent to the oocyte membrane. Several Vas-positive dots (arrowhead) are visible in the cytoplasm. Follicle cells (fc) surrounding the oocyte are weakly stained. (C,D,E) Nos signals are localized to the oocyte posterior (arrowhead). (C, E) Images taken in the same focal plane. A different focal plane in (D) shows the area of localized Nos staining extending to the lateral posterior. Nos positive dots are also apparent in the cytoplasm. (F-K) Embryos undergoing syncytial synchronous nuclear division with two nuclei. (F,G) Vas signals are not found in the cytoplasm. Inset in (G) is a magnification of the nucleus indicated with the arrow showing condensed chromosomes at early prophase. $\mathbf{( J , K ) ~ l o c a l i z a t i o n ~ o f ~ V a s ~ s i g n a l s ~ i s ~ f i r s t ~ i d e n t i f i e d ~ i n ~ t h e ~ e m b r y o ~ p o s t e r i o r ~ ( a r r o w h e a d ) . ~}$ Inset in $\mathrm{K}$ (is) a magnification of the nucleus indicated with the arrow showing that the pattern of chromosome condensation is at early metaphase.

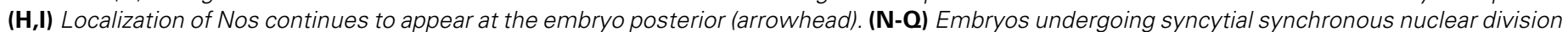
with eight nuclei. $(\mathbf{N}, \mathbf{O})$ Vas signals are localized to the lateral posterior (arrowhead). $(\mathbf{P}, \mathbf{Q})$ Nos signals are also identified at the posterior. The distribution of localized Nos signals occupies a smaller area than the Vas signals. (L,M) Negative controls (-ctrl). Almost no immunostaining signals are detected in stage-3 embryos without staining of primary antibodies. Vas or Nos positive dots are visible in all panels except for the -ctrl group. Scale bars: $20 \mu \mathrm{m}$.
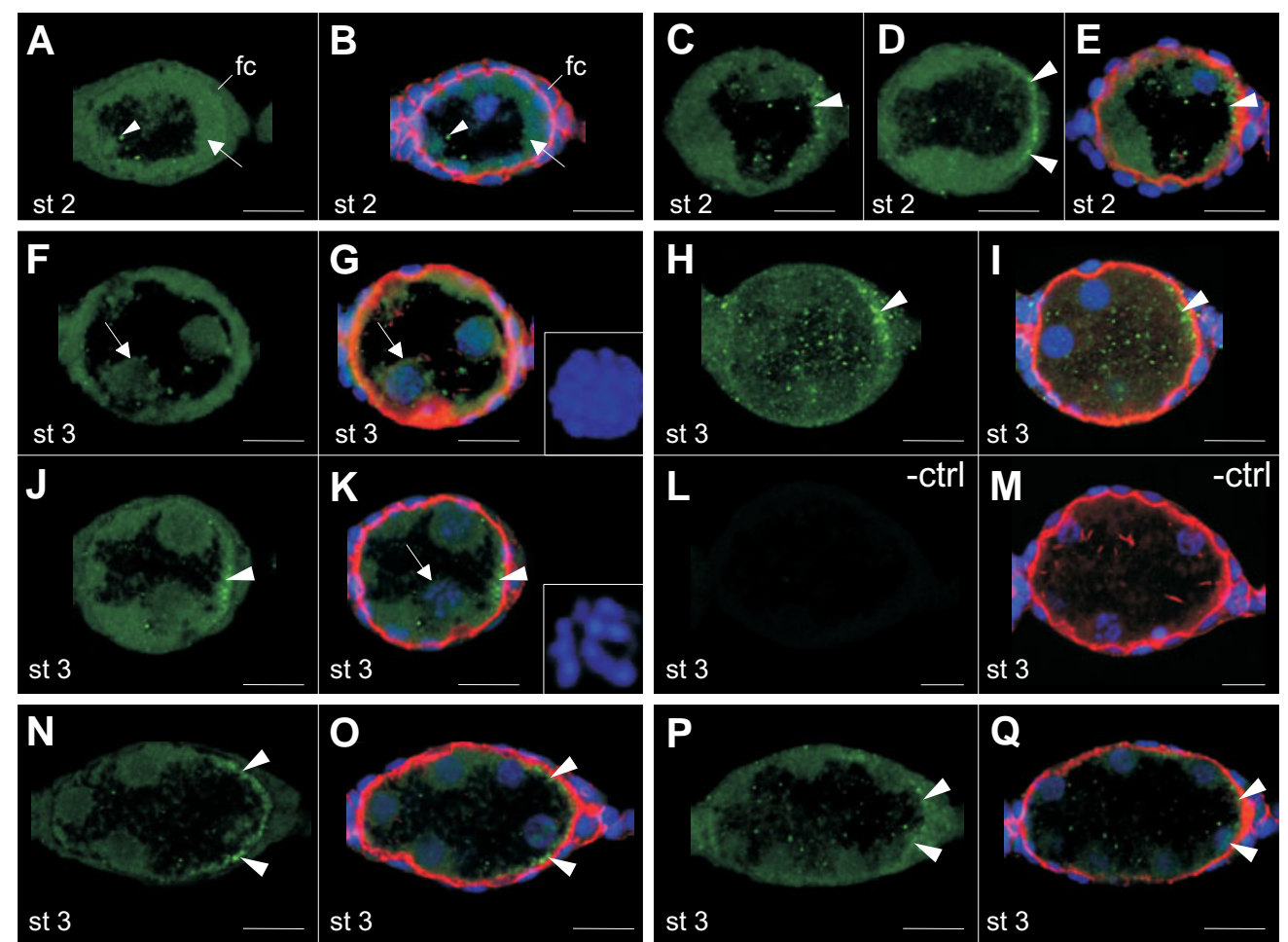

Vas/Nos Fuclei 
Nanos, which is an RNA-binding protein and a widely expressed germline marker (Saffman and Lasko, 1999; Extavour and Akam, 2003).

\section{Results}

\section{Expression of Vas and Nos in germaria and oocytes}

The ovariole of parthenogenetic pea aphids is telotrophic and meriostic; the germarium of this ovarian type is at the anterior tip of the ovariole. Previous studies have shown that in pea aphids the germarium contains nurse cells and prospective oocytes, from which the oocyte is derived (Büning, 1985; Miura et al., 2003). Antibodies against Vasa (Vas) and Nanos (Nos) stained the cytoplasm of nurse cells and prospective oocytes in the germarium (Fig. 1). In the developing oocyte (stage 0) the Nos signal was localized to the nuclear periphery (Fig. $1 \mathrm{~B}, \mathrm{D}$ ) whereas Vas was weakly expressed, in the cytoplasm (Fig. 1 A,C). Similar staining patterns were observed in the oocyte after separation from the germarium (stage 1), when Vas was distributed in the cytoplasm (Fig. 1 E,G,I) and Nos was localized to the nuclear periphery as well as to the granular material near the nuclear envelope (Fig. $1 \mathrm{~F}, \mathrm{H}, \mathrm{J}$ ).

\section{Expression of Vas and Nos before formation of the blasto- derm}

After separation of the oocyte from the germarium, the nuclear envelope disappears and the oocyte undergoes a single maturation division (stage 2; Fig. 2 A-E) (Miura et al., 2003). During this stage, Vas was evenly distributed in an area beneath the oocyte membrane with no distinct localization (Fig. 2 A,B). Some of the Nos, by contrast, accumulated at the posterior region of the oocyte, with the remainder distributed in the cytoplasm (Fig. 2 C-
E). Miura etal. (2003) state that embryogenesis begins with "early syncytial synchronous nuclear division". During this first mitotic division, no localized Vas signal was visible within the embryo when the nuclei contained condensed chromosomes at early prophase (Fig. 2 F,G). Thereafter, when mitotic division entered metaphase, Vas was first visible in a localized pattern at the posterior region of the embryo (Fig. $2 \mathrm{~J}, \mathrm{~K}$ ). Within the same stage, we observed that Nos was also continuously localized posteriorly in the embryo (Fig. $2 \mathrm{H}, \mathrm{I}$ ). In embryos with eight nuclei, similar patterns of posterior localization were observed with Vas and Nos staining (Fig. $2 \mathrm{~N}-\mathrm{Q}$ ). Almost no signal was identified in embryos that were not incubated with primary antibodies (Fig. 2 L,M).

\section{Expression of Vas and Nos during the formation of blasto- derm}

After four rounds of mitotic division, the 16 resulting nuclei migrated toward the periphery of the stage 4 uncellularized embryo (Fig. 3 A-D). We observed a localized Vas signal at the lateral posterior of the embryo (Fig. $3 \mathrm{~A}, \mathrm{~B}$ ), similar to that in stage 3 embryos (Fig. 2 J,K,N,O). The Nos signal was also localized to the lateral posterior at this stage (Fig. 3 C, D). In addition, Nos colocalized with the phalloidin-TRITC signal, which denoted the location of F-actin, over the entire embryonic inner periphery except for two narrow areas at the anterior and posterior respectively (Fig. 3 C,D). After cellularization, the blastoderm was formed in the stage 5 embryo (Fig. $3 \mathrm{E}-\mathrm{H}$ ). Both Vas and Nos antibodies stained the primordial germ cells (PGCs) in the posterior region of the egg (Fig. $3 \mathrm{E}-\mathrm{H}$ ). These correspond to the earliest germ cells in asexual aphids which have been reported in previous studies (Will, 1888; Miura et al., 2003). The signal patterns generated by these two antibodies were slightly different: the Vas signal was distributed in the cytoplasm (Fig. 3 E,F), while the Nos

Fig. 3. Vas and Nos signals in embryos from stage 4 to stage 6 of development. Signals representing Vas or Nos immunoactivity, F-actin adjacent to the inner surface of cell membranes and nuclei are indicated with color keys under the figure. Anterior is to the left and posterior is to the right in all panels. Confocal images showing $\operatorname{Vas}(A, E, I)$ or Nos $(C, G, K)$ antibody staining. Confocal images showing merged results from $(B, F, J)$ Vas and $(D, H, L)$ Nos antibody, nuclei and F-actin staining. (A-D) Embryos at stage (st) 4 of development. (A,B) Embryo stained with Vas antibody. Vas signals are localized to the lateral posterior (arrowhead). (C,D) Embryo stained with Nos antibody. Nos signals are visible along the lateral edges of the embryo (arrow), but these signals are disjunctive at the center and

Vas
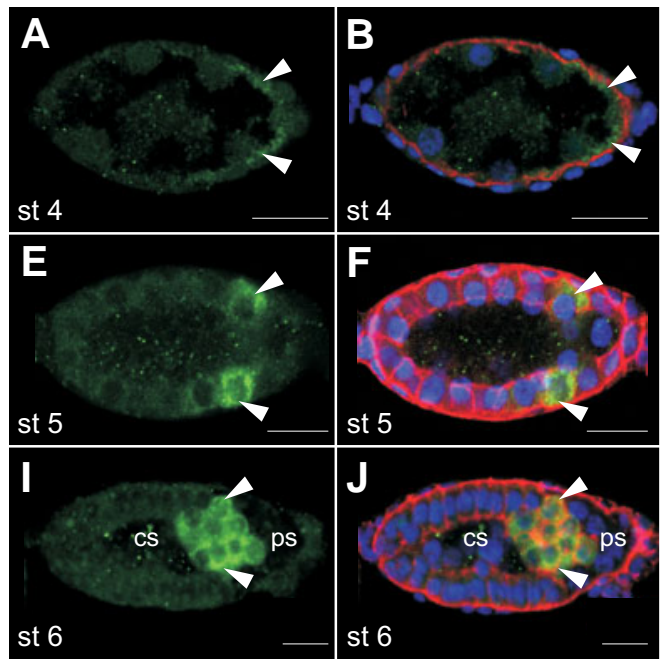

Vas/Nos
Nos
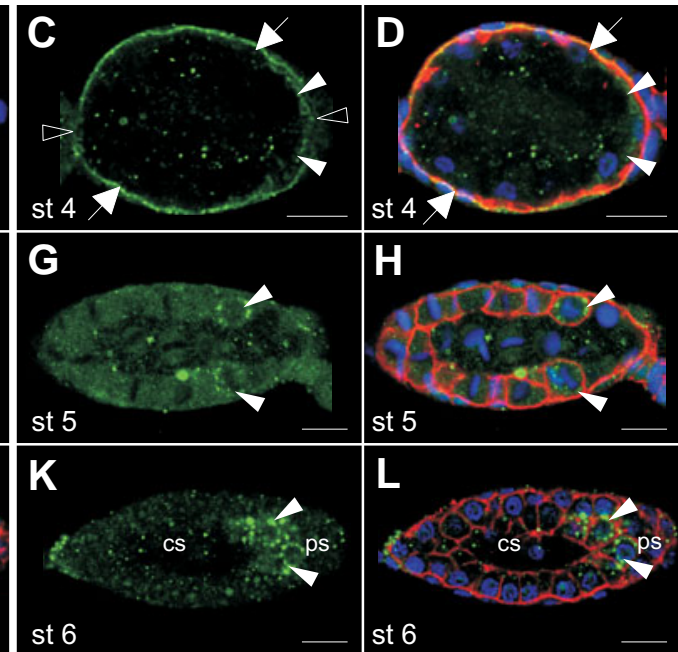

st 6

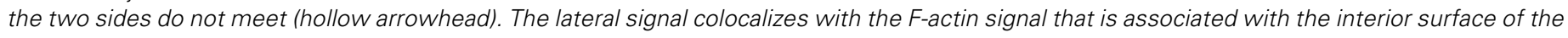

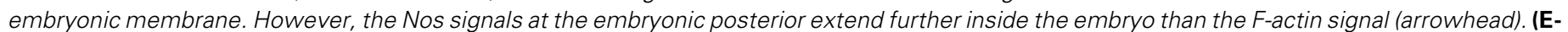

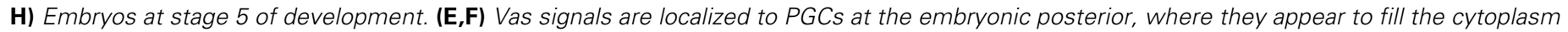

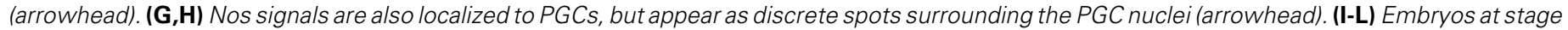

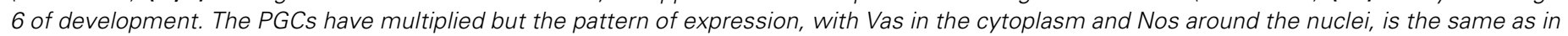
stage 5. cs, central syncytium; ps, posterior syncytium. Scale bars: $20 \mu \mathrm{m}$. 
Fig. 4. Vas signals and germ cells in embryos during mid and late embryogenesis. Anterior is to the left and posterior is to the right in all panels unless otherwise noted. Dorsal is uppermost. (A) Lateral view of embryo at stage (st) 7 of development. Endosymbiotic bacteria (b) are incorporated into the embryo from the posterior. Boundary of the bacteria is highlighted with dashed lines. PGCs (arrowhead) reside dorsally to the bacteria. (B) Lateral view of embryo at stage 11 of development. The germ band folds into an $S$ shape which is not clear in this focal plane. PGCs (arrowhead) are pushed dorsally, adjacent to the endosymbiotic bacteria (b), at the anterior of the egg chamber. (C) A dorsolateral view of an embryo at stage 13 of development. The head ( $h$ ) is to the right and the future abdomen ( $\mathrm{fa}$ ) is to the left. This embryo is stretched a bit from dorsal to lateral so that the newly-formed limb buds (white dots) are visible at the ventral posterior. In this focal plane the endosymbiotic bacteria, which are situated between the future abdomen and PGCs (arrowhead), are not in focus. (D-F) A dorso-lateral view of the embryo at stage 17 of development. After katatrepsis, the head (h) turns to the left. T1-T3: location of the thoracic (T) segments 1-3. (D) Vas signals (arrowhead) are identified in the abdomen undergoing germ-band retraction. (E) A nuclear staining of the embryo in (D) with DAPI, shown as a lateral view. Cells with Vas signals (ar-
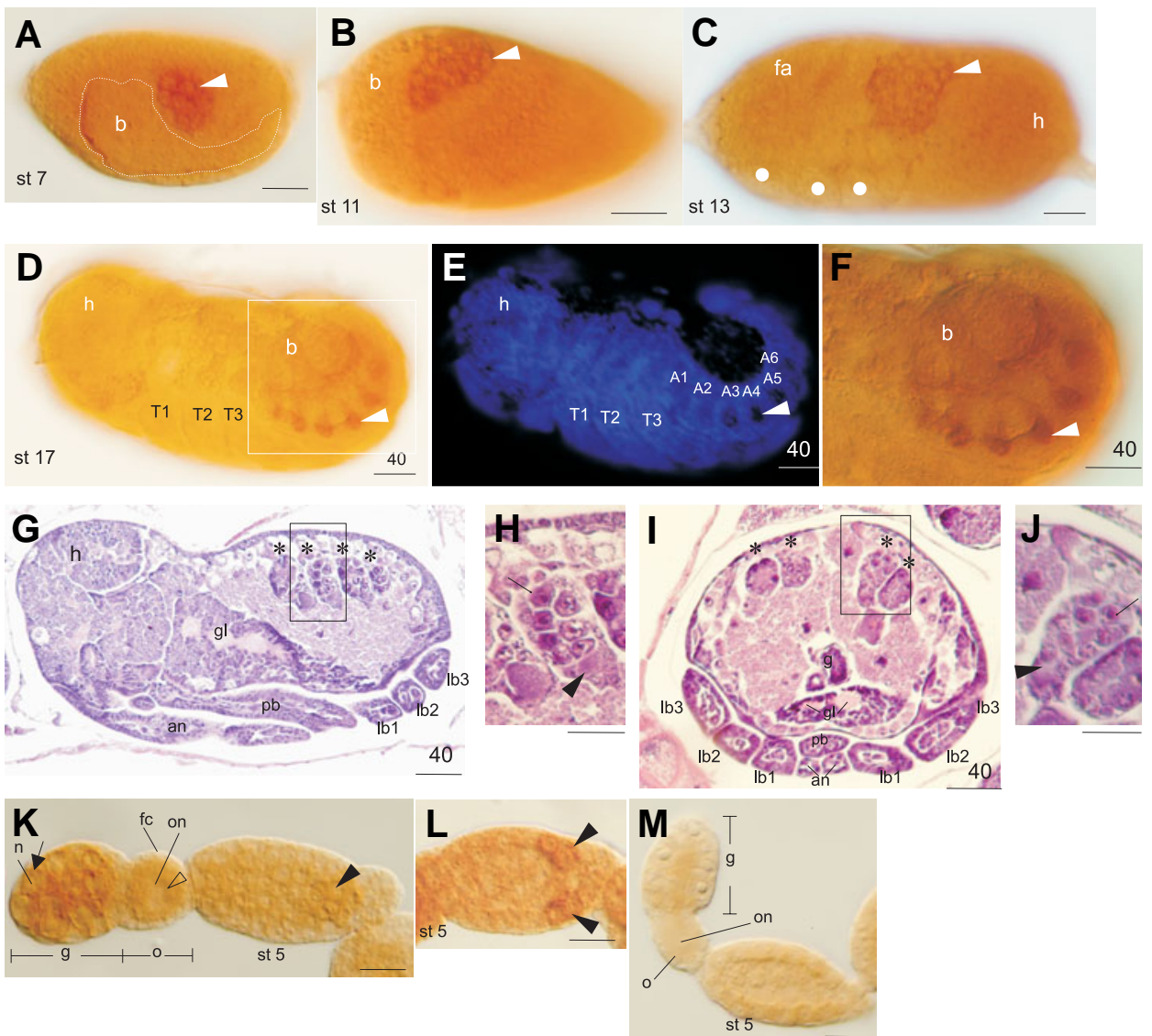

rowhead) quench DAPI signals within abdominal (A) segments A1 to A6. (F) A magnification of the inset in (D). Six subclusters of Vas-positive cells are apparent in the abdomen and they are adjacent to the bacteria (b). (G-J) Embryonic sections stained with Hematoxylin and Eosin. (G) Longitudinal section through a mature embryo. Asterisks show the location of young ovarioles. The head (h), antenna (an), ganglion (gl), proboscis (pb) and three limb buds (Ib) are marked. (H) Magnification of inset in (G) showing close up of nuclei (arrow) in the germarium. The arrowhead indicates the location of the future oocyte. Note that the oocyte nucleus is not yet visible in this space. (I) Transverse section of a mature embryo. Labels as in (H). (J) Magnification of inset in (I) showing nuclei (arrow) in the germarium. The arrowhead indicates the nucleus in the newly formed oocyte. (K) Ovariole dissected from the most mature embryo stained with the Vas antibody showing cytoplasmic staining in the nurse cells (n and arrow) in the germarium (g), the oocyte (o) and cells within the stage 5 embryo. The nucleus of the separated oocyte (on) and the follicle cells (f) are devoid of staining and there is no localization of a Vas signal in the nuclear periphery (hollow arrowhead). Solid arrowhead shows location of PGCs with slightly stronger Vas signals in a stage 5 embryo, as shown in (L). (L) A more mature stage 5 embryo dissected from the same individual as that shown in (K). Arrowheads show localized Vas signals in PGCs of the embryo. (M) Negative control (no primary antibody) of the ovariole from a different individual. Scale bars $20 \mu \mathrm{m}$ unless otherwise indicated.

signal was localized to the nuclear periphery, appearing as dotty granules similar to the pattern seen in the oocytes (Fig. 3 G,H; Fig. 1 , Nos column). Moreover, the Nos signal in the embryonic periphery of the uncellularized embryo (Fig. 3 C,D) was downregulated in the cellularized embryo at stage 5 of development so that it was restricted to the PGCs (Fig. 3 G,H). From stage 6 onward, the PGCs multiplied and began to migrate toward the embryonic center, creating two subspaces, namely a central syncytium and a posterior syncytium, within the embryo (Fig. 3 IL) (Miura et al., 2003). The PGCs themselves were stained with both Vas and Nos antibodies (Fig. 3 I-L).

\section{Identification of germ cells in embryos during mid and late development}

We identified germ cells in embryos from stage 7 of development, a stage prior to gastrulation, to mature stages with our cross-reacting Vas antibody only. The Nos antibody appeared less specific to germline from stage 7 onward so that we did not use it to trace germ-cell migration in parallel. The endosymbiotic bacteria first invaded the embryo during stage 7 and the Vas antibody stained PGCs located dorsally to the invading bacteria (Fig. 4A). During gastrulation, PGCs were pushed by the invaginating germ band and they reach the dorsal site at stage 11, which is characterized by an S-shaped germ band (Fig. 4B) (Miura et al., 2003). PGCs remained as a cluster at the dorsal site at stage 13 of development, during which limb buds began to grow (Fig. 4C). From stages 14 to 16 , the PGC cluster was still located dorsally, appearing not to be affected by the germ-band extension (stage 14) and katatrepsis (stage 15) (Miura et al., 2003 and data not shown). Interestingly we found that germ cells were grouped within segments in embryos during germ-band retraction (stage 17). Sub-clusters of these germ cells reside in abdominal segments from A1 to A6 (Fig. 4 D-F). We have not successfully stained germ cells with the cross-reacting Vas antibody on sec- 
tioned embryos at later developmental stages, but we were able to observe germ cells in the young ovarioles with Hematoxylin and Eosin (H\&E) staining (Fig. 4 G-J). These germ-cell containing ovarioles were located dorsally and they already embodied germaria and oocytes with primitive shapes (Fig. $4 \mathrm{H}, \mathrm{J}$ ). Ovarioles dissected from the most mature embryos were also stained and a Vas signal was identified in the cytoplasm of nurse cells and oocytes (Fig. $4 \mathrm{~K}, \mathrm{~L}$ ), similar to the staining results shown in Fig. 1. In most ovarioles dissected from mature embryos, PGCs were not preferentially stained (Fig. 4K). Nevertheless, we could still identify localized Vas signals in the stage 5 embryo in a small proportion of ovarioles.

\section{Discussion}

In this study, we used antibodies against Vas and Nos to stain ovarioles containing oocytes and embryos in the parthenogenetic pea aphid Acyrthosiphon pisum. Both antibodies specifically identified signals localized to the cytoplasm in cells that corresponded to the known positions of PGCs in asexual aphids from stage 5 to 6 of development (Fig. 3 E-L) (Will, 1888; Hagan, 1951; Miura et al., 2003), suggesting that Vas and Nos proteins are germline markers in pea aphids. Given that Vas and Nos are two conserved components of the germ plasm in many other species (Saffman and Lasko, 1999; Extavour and Akam, 2003), localized signals before stage 5 of development are regarded as markers to trace the specification of germ plasm. In addition to the localized signals, we observed background staining in the nuclei of germarial cells stained with the Nos antibody (Fig. 1B). Such staining was not seen in Drosophila(Verrotti and Wharton, 2000). Background staining was also visible in the cytoplasm of somatic cells stained with the Vas and Nos antibodies throughout development. These background signals were generated by the primary antibodies because almost no signals were detectable in controls lacking the antibodies against Vas or Nos (Fig. 2L; Fig. $4 \mathrm{M}$ ). The background staining may be caused by non-specific recognition to other proteins that are neither Vas nor Nos. However, we cannot rule out the possibility that such staining represents the basal expression of Vas or Nos.

Our results show that Nos signals, rather than Vas, are localized to the nuclear periphery in both the developing oocyte (stage 0 ; Fig. 1 B,D) and the oocyte segregated from the germarium (stage 1; Fig. $1 \mathrm{~F}, \mathrm{H}, \mathrm{J}$ ). Localized Nos signals, including those identified in the cytoplasmic granules, are then shifted to the posterior of the oocyte undergoing maturation division and a pattern of posterior localization is continuously identified in embryos from nuclear division to the formation of the syncytial blastoderm (stage 2-4; see Nos columns in Figs 2 and 3). This suggests that Nos signals localized to the PGCs in the embryonic posterior at stage 5 of development are inherited from the Nos signals restricted to the posterior during earlier development. There is no direct evidence (which would require real-time monitoring) to show that the posterior localization of Nos originates from Nos protein localized to the nuclear periphery and in granular particles in the cytoplasm. However, the disappearance of the peripheral nuclear localization of the Nos signal followed by its reappearance in the posterior (Fig. 1 F,H; Fig. 2 C-E), strongly suggests that components of these two subcellular areas are closely related. This suggestion is also applicable to the transition of Nos expression from granules in the cytoplasm to the posterior (Fig. 1 F,H; Fig. 2 C-E). In effect, we observe tiny dots of Nos scattered in the cytoplasm, which are not apparent in the ovariole without incubation with primary antibodies, coexisting with the localized Nos at the posterior in the late oocyte (stage 2; Fig. 2 C,E). These Nos-positive dots, which have a signal intensity stronger than that of the staining background, may represent Nos protein that was previously associated with the nuclear envelope and cytoplasmic granules migrating toward the posterior. Furthermore, the localization of Nos to the dense particles surrounding the nuclear envelope resembles the nuage, which is a perinuclear structure embodying electron-dense materials containing germline determinants in many species (Eddy, 1975; Kloc et al., 2004). This morphological resemblance reinforces our hypothesis that the perinuclear localization of Nos in the early oocytes represents the location of the germ-plasm precursor. Nevertheless, we cannot rule out the possibility, which is based upon a recent study arguing the "precursor-product" relationship between nuage and polar granules in Drosophila, that it is Nos itself, rather than the nuage structure, being localized to the posterior (Snee and Macdonald, 2004).

Unlike Nos, posterior localization of Vas is not identified until the embryo initiates the second syncytial nuclear division at metaphase (Fig. 2 J,K). During earlier development, several Vaspositive dots are randomly distributed in the cytoplasm of developing oocytes but these are not particularly restricted to the nuclear periphery (Fig. $1 \mathrm{~A}, \mathrm{C}$ ). In the segregated oocyte, signals of weak Vas localization are not visible (Fig. 1 C,G,I), suggesting that Vas may not be a component of the nuage or of any other type of germ-plasm precursor. Nevertheless, posterior localization of Vas can be continuously identified in the stage 3 embryo after initiation of the second mitotic division and these Vas signals are localized to the PGCs in the stage 5 embryo (Fig. 3 E,F). This result shows that Vas is indeed a conserved germline marker in parthenogenetic pea aphids, although it is not the earliest such marker. In Drosophila, both Vas and Nos are also components of the germ plasm (Hay et al., 1988b; Wang and Lehmann, 1991). However, localization of nos mRNA to the pole plasm in the posterior region of the oocyte depends on vas as well as other posterior group genes such as staufen, oskar, valois and tudor (Lehmann and Nusslein-Volhard, 1991). In addition, the translation of nos mRNA is initiated when it is localized to the posterior area of the oocyte (Gavis and Lehmann, 1994), whereas Vas is localized earlier than Nos in the nuage in nurse cells and then in the posterior pole of oocytes (Hay et al., 1988a). In Schistocerca gregaria (grasshopper) both Vas and Nos are localized to the germline stem cells and early oocytes; however, only Vas is identified in the segregated germ cells while Nos is not (Chang et al., 2002; Lall et al., 2003). It is apparent that the modes of utilization of Vas and Nos as germline markers in insects are diversified, so we cannot use studies from other insects to infer whether the early localization of Nos depends on Vas in the developing oocyte (Fig. 1 B,D) or vice versa in the stage-3 embryo of aphids (Fig. $2 \mathrm{~J}, \mathrm{~K}$ ).

Our staining of germ plasm and PGCs in parthenogenetic pea aphids agrees with previous morphological studies of germ-cell development in other viviparous aphids. In the rose louse Aphis rosae, Paspaleff (1929) observed a vacuolated area restricted to the posterior region of the egg soon after the polar body was given 
off during the maturation division. He suspected it was the germ plasm but was unable to confirm that identification using the techniques he had available (Paspaleff, 1929). The location of this vacuolated area is similar to the posterior localization of Nos and Vas in stage 2 oocytes and early stage 3 embryos in pea aphids (Fig. 2), suggesting that the posterior area contains germ plasm in both species. Vas positive cells identified in embryos undergoing gastrulation (Fig. 4 A-C) match the locations of PGCs described in a recent study of pea aphid development by Miura et al. (2003) and they are also similar to the positions of germ cells at equivalent stages reported in species such as Aphis pelargonii (currently known as Acyrthosiphon malvae) (Will, 1888; Eastop and Hille Ris Lambers, 1976) and Brevicoryne brassicae (Bruslé, 1962). This evidence shows that the cells preferentially expressing Vas from gastrulation onward are PGCs. Taken together, common features of PGCs in these three aphid species are: (1) PGCs are pushed by the elongating germ band invaginating into the embryonic cavity (Fig. 4 A,B); (2) PGC migration is associated with the endosymbiotic bacteria (Fig. 4 A,B,D); (3) PGCs remain dorsal in the egg even after katatrepsis (Fig. 4 B,C,D,G,I).

Coalescence between migratory PGCs and the embryonic gonad is an important event for germ-cell development. Previous descriptions of aphid embryogenesis provide little information on this issue. According to Will (1888), the formation of germaria in Aphis pelargonii (Acyrthosiphon malvae) was identified in embryos bearing germ-band retraction. Our investigation of germ cells in $A$. pisum at equivalent stages shows that germ cells aggregate as germarium-like structures within abdominal segments (stage 17; Fig. $4 \mathrm{D}-\mathrm{F}$ ), which is in agreement with Will's study. According to Miura et al. (2003), germ cells still aggregate dorsally in the egg after katatrepsis (stage 15). We thus infer that the segmentation of germ cells takes place during the time window of germ-band retraction. We hypothesize that germ cells disassociate from their dorsal site and migrate to coalesce with segmented gonadal mesoderm within the embryonic cavity. After coalescence, gonads containing germ cells differentiate to form germarial primordia and these later move to a dorsal position in each segment where they develop into young ovarioles (Fig. 4 $\mathrm{G}, \mathrm{I})$. Vas signals localized to the germarium and PGCs in the stage 5 embryos are also identified in ovarioles dissected from the mature embryos (Fig. $4 \mathrm{~K}, \mathrm{~L}$ ). This suggests that Vas is a germline marker in pea aphids throughout all developmental stages, except for the early stages of oocyte segregation and the maturation division, during which no localized Vas is identifiable (Vas columns in Fig. 1 and Fig. 2). With regard to Nos, it is clear that this protein marks germ cells very early in development, but whether it persists as a germline marker in embryos after gastrulation requires further investigation.

Our work extends the understanding of germ-cell development and in particular germ-cell specification in parthenogenetic pea aphids. The formation of germ cells in the asexual reproductive phase of $A$. pisum depends, as it does also in Drosophila, on germline determinants at the posterior region of the egg. We hypothesize that a "molecular anchor" at the posterior, such as oskarin Drosophila (Ephrussi and Lehmann, 1992), controls the localization of molecules required for germ-cell specification. Although the pattern of germ cell formation in aphids and flies seems similar, our observations, as well as those of Miura et al. (2003), provide no evidence that germ cells in aphids are among the first cellularized cells of the forming blastoderm. We have not in this study addressed the formation of germ cells in the sexual phase of the pea aphid life cycle. Previous studies have shown that germ-cell formation in the sexual phase is rather different from the asexual phase and morphological studies suggest that germ cells in the sexual phase segregate later than in the asexual phase (Baker and Turner, 1916; Miura et al., 2003). We suggest that Vas and Nos would also be useful as germline markers for studying germ-cell development in the sexual phase of $A$. pisum.

\section{Materials and Methods}

\section{Insects}

Parthenogenetic pea aphids, Acyrthosiphon pisum, were provided by the laboratory of Dr. M. H. Kuo, National Chung Hsing University in central Taiwan. Aphids were reared on garden pea plants, Pisum sativum, at $12^{\circ} \mathrm{C}$ in a growth chamber with a photo period of 16 hours light/ 8 hours dark. Staging of pea aphids is based upon the scheme of Miura et al. (2003)

\section{Immunocytochemistry and microscopy}

Ovarioles containing oocytes and embryos were dissected from apteriform adults in pre-chilled $1 \mathrm{X}$ phosphate buffered saline (PBS: 137 $\mathrm{mM} \mathrm{NaCl} ; 2.68 \mathrm{mM} \mathrm{KCl} ; 1.47 \mathrm{mM} \mathrm{KH}_{2} \mathrm{PO}_{4} ; 8.10 \mathrm{mM} \mathrm{Na}_{2} \mathrm{HPO}_{4}$; $\mathrm{pH} 7.0$ ), followed by fixation in $3.8 \%$ formaldehyde in $1 \mathrm{X}$ PBS for 20 minutes at room temperature. Dissected ovarioles were washed three times for 10 minutes with $0.2 \%$ Triton-X 100 (Sigma) in 1 X PBS (1X PTx). After washing off the formaldehyde, ovarioles were treated with $0.6 \% \mathrm{H}_{2} \mathrm{O}_{2}$ in 1x PBS for 20 to 30 minutes at room temperature to bleach endogenous peroxidase activity. $\mathrm{H}_{2} \mathrm{O}_{2}$ was washed off with 1 X PTx three times for 10 minutes and then ovarioles were blocked with $5 \%$ Normal Donkey Serum (NDS; Jackson Laboratories)/0.5\% Bovine Serum Albumin (BSA; Sigma) in $1 \mathrm{X} \mathrm{PTx}$ at $4^{\circ} \mathrm{C}$ overnight. Endogenous biotin activity was blocked with an Avidin/Biotin Blocking kit (Vector Laboratories). Ovarioles were then stained with primary antibodies of appropriate dilution (Vas (formosa 2) antibody: 1:40 (Chang et al., 2002); Nos antibody: 1:250 (a kind gift from Drs A. Nakamura and S. Kobayashi) (Hanyu-Nakamura et al., 2004); both antibodies were made from rabbits)), $4^{\circ} \mathrm{C}$ overnight. Samples incubated with primary antibodies were washed with 1X PTx four times for 15 minutes. Ovarioles were then blocked with NDS/BSA in 1X PTx for 30 minutes to one hour, followed by secondary-antibody staining for 2 to 4 hours at room temperature. For fluorescent microscopy, we used Alexa Fluor $^{\circledR} 488$ goat anti-rabbit $\lg G(\mathrm{H}+\mathrm{L})(1: 500$; Invitrogen); for light microscopy, we used biotinylated anti-rabbit IgG (1:200; Vector Laboratories). Secondary antibodies were washed off with 1 X PTx four times for 15 minutes. For samples stained with fluorescent secondary antibody, we also used DAPI (Sigma; $2 \mathrm{ng} / \mu \mathrm{l}$ ) for nuclear staining and Phalloidin TRITC (Sigma; $100 \mathrm{nM}$ ) for F-actin staining and mounted them in VECTASHIELD ${ }^{\circledR}$ mounting medium (Vector Laboratories). For embryos stained with biotinylated secondary antibodies, signal development was performed with a VECTASTAIN ${ }^{\circledR}$ Elite ABC Kit (Vector Laboratories). DAPI staining was performed after signal development. Samples were then mounted in $70 \%$ glycerol in 1 xPBS. HE staining was performed according to standard protocols. Confocal images were taken with a Zeiss LSM510 META; DIC (differential interference contrast) images of wholemount samples and sectioned slides were photographed with a Leica DMR connected to a Fuji FinePix S2 Pro digital camera.

We also performed western blots on dissected ovarioles from adult aphids by using the Vas and Nos antibodies, aiming to determine whether these antibodies cross-react with more than one protein. This work showed that both antibodies react strongly with a single major band within expected size ranges (data not shown), suggesting that the localized signals with strong intensity in the immunostaining samples are the Vas 
or Nos proteins.

\section{Acknowledgements}

We are grateful to $A$. Nakamura and S. Kobayashi for the provision of Drosophila Nanos antibody; the Akam Laboratory for posting the formosa antibody; B.C. Chung for crucial support on confocal microscopy; I. C. Guo and $Y$. N. Chiou for assistance with HE staining; T. Y. Huang for the confirmation of staining late embryos; $M$. H. Kou for pea aphids; T. P. Chang for careful manuscript proofreading. C.C. thanks MichaelAkam for initiating him to the world of insect germline; David Stern and Toru Miura for the knowledge of aphid development; R. H. Juang, S. B. Horng and H. $J$. Lee for lab set up. This work was supported by the National Science Council of Taiwan (93-2313-B-002-046; 93-2313-B-002-047) and the Academia Sinica.

\section{References}

BAKER, A.C. and TURNER, W.F. (1916). Morphology and biology of the green apple aphis. J. Agric. Res. 5: 955-993.

BLACKMAN, R.L. (1987). Chapter 3. Reproduction, Cytogenetics and Development. In Aphids: their biology, natural enemies and control, vol. A (ed. MINKS, A. K. and HARREWIJN, P.). Elsevier, pp.163-195.

BRAAT, A.K., SPEKSNIJDER, J.E. and ZIVKOVIC, D. (1999). Germ line development in fishes. Int. J. Dev. Biol. 43: 745-760.

BRUSLÉ, S. (1962). Chronologie du développement embryonnaire des femelles parthénogénétiques de Brevicoryne brassicae(Aphididae: Homoptères). Bulletin de la Société Zoologique de France 87: 396-410.

BÜNING, J. (1985). Morphology, ultrastructure and germ-cell cluster formation in ovarioles of aphids. J. Morphol. 186: 209-221.

CARRERA, P., JOHNSTONE, O., NAKAMURA, A., CASANOVA, J., JÄCKLE, H. and LASKO, P. (2000). VASA mediates translation through interaction with a Drosophila ylF2 homolog. Mol. Cel/5: 181-187.

CHANG, C.C., DEARDEN, P. and AKAM, M. (2002). Germ line development in the grasshopper Schistocerca gregaria: vasaas a marker. Dev. Biol. 252: 100-118.

DONNELL, D.M., CORLEY, L.S., CHEN, G. and STRAND, M.R. (2004). Caste determination in a polyembryonic wasp involves inheritance of germ cells. Proc. Natl. Acad. Sci. USA. 101: 10095-10100.

EASTOP, V.F. and HILLE RIS LAMBERS, D. (1976). Survey of the world's aphids. The Hague: Junk.

EDDY, E.M. (1975). Germ plasm and the differentiation of the germ cell line. Int. Rev. Cytol. 43: 229-280.

EPHRUSSI, A. and LEHMANN, R. (1992). Induction of germ cell formation by oskar. Nature 358: 387-392.

EXTAVOUR, C.G. (2005). The fate of isolated blastomeres with respect to germ cell formation in the amphipod crustacean Parhyale hawaiensis. Dev. Biol. 277: 387-402.

EXTAVOUR, C.G. and AKAM, M. (2003). Mechanisms of germ cell specification across the metazoans: epigenesis and preformation. Development 130: 58695884.

EXTAVOUR, C.G., PANG, K., MATUS, D.Q. and MARTINDALE, M.Q. (2005). vasa and nanos expression patterns in a sea anemone and the evolution of bilaterian germ cell specification mechanisms. Evol. Dev. 7: 201-215.

FUJIWARA, Y., KOMIYA, T., KAWABATA, H., SATO, M., FUJIMOTO, H., FURUSAWA, M. and NOCE, T. (1994). Isolation of a DEAD-family protein gene that encodes a murine homolog of Drosophila vasa and its specific expression in germ cell lineage. Proc. Natl. Acad. Sci. USA. 91: 12258-12262.

GAVIS, E.R. and LEHMANN, R. (1994). Translational regulation of nanos by RNA localization. Nature 369: 315-318.

GAVIS, E.R., LUNSFORD, L., BERGSTEN, S.E. and LEHMANN, R. (1996). A conserved 90 nucleotide element mediates translational repression of nanos RNA. Development 122: 2791-2800.

GRBIC, M. (2000). «Alien» wasps and evolution of development. Bioessays 22: 920-932.

HAGAN, H.R. (1951). Chapter 13. Pseudoplacental viviparity-Corrodentia, Hemiptera (Aphididae). In Embryology of the Viviparous Insects. Roland Press, New
York, pp.347-392.

HANYU-NAKAMURA, K., KOBAYASHI, S. and NAKAMURA, A. (2004). Germ cellautonomous Wunen2 is required for germline development in Drosophila embryos. Development 131: 4545-4553.

HAY, B., ACKERMAN, L., BARBEL, S., JAN, L.Y. and JAN, Y.N. (1988a). Identification of a component of Drosophila polar granules. Development 103: 625640.

HAY, B., JAN, L.Y. and JAN, Y.N. (1988b). A protein component of Drosophilapolar granules is encoded by vasa and has extensive sequence similarity to ATPdependent helicases. Cel/55: 577-587.

HEGNER, R. (1908). Effects of removing the germ-cell determinants from the eggs of some chrysomelid beetles. Prelim. Rept. Biol. Bull. 16: 19-26.

HEIDER, K. (1889). Die embryonalentwicklung von Hydrophilus piceus L. Gustav Fischer, Jena, pp.98.

IKENISHI, K. and TANAKA, T.S. (2000). Spatio-temporal expression of Xenopus vasahomolog, XVLG1, in oocytes and embryos: The presence of XVLG1RNAs in somatic cells as well as germline cells. Dev. Growth Differ. 42: 95-103.

INKMANN, F. (1933). Beiträge zur Entwicklungsgeschichte des Kornkäfers (Calandra granaria). Die Anfangsstadien der Embryogenese. Zool. Jahrb. (Anat.)56: 521558.

JOHANNSEN, O.A. and BUTT, F.H. (1941). Chapter IV. Early Development. In Embryology of Insects and Myriapods. McGRAW-HILL Book Company, Inc., New York and London, pp.33-48.

KLOC, M., BILINSKI, S. and ETKIN, L.D. (2004). The Balbiani body and germ cell determinants: 150 years later. Curr. Top. Dev. Biol. 59: 1-36.

KOMIYA, T., ITOH, K., IKENISHI, K. and FURUSAWA, M. (1994). Isolation and characterization of a novel gene of the DEAD box protein family which is specifically expressed in germ cells of Xenopus laevis. Dev. Biol. 162: 354-363.

LALL, S., LUDWIG, M.Z. and PATEL, N.H. (2003). Nanos plays a conserved role in axial patterning outside of the Diptera. Curr. Biol. 13: 224-229.

LASKO, P.F. and ASHBURNER, M. (1988). The product of the Drosophila gene vasa is very similar to eukaryotic initiation factor-4a. Nature 335: 611-617.

LEHMANN, R. and NUSSLEIN-VOLHARD, C. (1991). The maternal gene nanos has a central role in posterior pattern formation of the Drosophila embryo. Development 112: 679-691.

LEUCKART, R. (1865). Die ungeschlechtliche Fortpflanzung der Cecidomyienlarven. Arch. f. Naturg. 31: 286-303.

MARKUSSEN, F.H., BREITWIESER, W. and EPHRUSSI, A. (1997). Efficient translation and phosphorylation of oskar require Oskar protein and the RNA helicase Vasa. Cold Spring Harb. Sym. 62: 13-17.

MIURA, T., BRAENDLE, C., SHINGLETON, A., SISK, G., KAMBHAMPATI, S. and STERN, D.L. (2003). A comparison of parthenogenetic and sexual embryogenesis of the pea aphid Acyrthosiphon pisum (Hemiptera: Aphidoidea). J. Exp. Zool. 295: 59-81.

MOSQUERA, L., FORRISTALL, C., ZHOU, Y. and KING, M.L. (1993). A mRNA localized to the vegetal cortex of Xenopus oocytes encodes a protein with a nanos-like zinc finger domain. Development 117: 377-386.

NAKAO, H. (1999). Isolation and characterization of a Bombyx vasa-like gene. Dev. Genes Evol. 209: 312-316.

NELSON, J.A. (1915). The Embryology of the Honey Bee. Princeton University Press.

PASPALEFF, G.W. (1929). Ovarialschläuche und Ooziten bei den parthenogenetischen Generationen von Aphis rosae, Koch und Siphonophora rosarum, Koch. (Bulgarian with German summary). Ann. Univ. Sofia, 2 Fac. phys.-mat. 25: 238-272.

RAZ, E. (2000). The function and regulation of vasa-like genes in germ-cell development. Genome Biol. 1: REVIEWS 1017.1-1017.6.

SAFFMAN, E.E. and LASKO, P. (1999). Germline development in vertebrates and invertebrates. Cell. Mol. Life Sci. 55: 1141-1163.

SAITOU, M., BARTON, S.C. and SURANI, M.A. (2002). A molecular programme for the specification of germ cell fate in mice. Nature 418: 293-300.

SNEE, M.J. and MACDONALD, P.M. (2004). Live imaging of nuage and polar granules: Evidence against a precursor-product relationship and a novel role for Oskar in stabilization of polar granule components. J. Cell Sci. 117: 2109-2120. 
STYHLER, S., NAKAMURA, A., SWAN, A., SUTER, B. and LASKO, P. (1998). vasa is required for Gurken accumulation in the oocyte and is involved in oocyte differentiation and germline cyst development. Development 125: 1569-1578.

SWANSON, M.M. and POODRY, C.A. (1980). Pole cell formation in Drosophila melanogaster. Dev. Biol. 75: 419-30.

TOMANCAK, P., GUICHET, A., ZAVORSZKY, P. and EPHRUSSI, A. (1998). Oocyte polarity depends on regulation of gurken by Vasa. Development 125: 1723-1732.

TSUDA, M., SASAOKA, Y., KISO, M., ABE, K., HARAGUCHI, S., KOBAYASHI, S. and SAGA, Y. (2003). Conserved role of Nanos proteins in germ cell development. Science 301: 1239-1241.

VERROTTI, A.C. and WHARTON, R.P. (2000). Nanos interacts with Cup in the female germline of Drosophila. Development 127: 5225-5232.

WANG, C. and LEHMANN, R. (1991). Nanos is the localized posterior determinant in Drosophila. Cel/66: 637-647.

WILL, L. (1888). Entwicklungsgeschichte der viviparen Aphiden. Zool. Jahrb. (Anat.) 3: 201-286.

ZHUROV, V., TERZIN, T. and GRBIC, M. (2004). Early blastomere determines embryo proliferation and caste fate in a polyembryonic wasp. Nature 432: 764769.

Received: September 2005

Reviewed by Referees: November 2005

Modified by Authors and Accepted for Publication: January 2006 